\title{
A METHOD OF DETERMINING ORGANIC NITROGEN IN LIQUIDS.
}

By A. Wynter Buyth, M.R.C.S., F.I.C.

Read before the Sooiety of Public Analysts, on June 18th, 1884.

Trie method of oxidation by means of sulphuric acid in excess and permanganate of potash is not a new one. The process in its details, nevertheless, was recently much improved by Vijeldahl (Zeits fux Analytische Ohemie "Hefl. 3, 1883") and proposed by him as a moist process of combustion. Still more recently 1r. Petri and Th. Lehmann ("Zeitsoh fux Physiologische Chemie, Band VIII., Hefl. 3, 1884") have published an account of an extremely prolonged and exhaustive research, as to its accuracy in determining the total nitrogen in urine; and have somewhat improved the details. I contributed in April of this year, to the Royal Society, a paper on the ingesta and egesta of Edward Payson Weston, and gave incidentally, a brief description of this method which I had applied with great advantage to the estimation, day by day, of the total nitrogen of the pedestrian's urine, as follows :-

Two grams of the urine were placed in a flask and 20 cubic centems of pure sulphuric acid added; heat was applied by means of a small flame for two or three hours, at the end of which time crystals of permanganate were added until the liquid was first decolourised, and then given a distinct dark pink or red tint. On now alkalising with pure oxide, all the nitrogen present was distilled over as ammonia; the distillation being assisted by a current of hydrogen gas, the ammoniacal distillate was received in a known quantity of standard decinormal acid and titrated back by decinormal soda. I have since made a number of analyses of flour and farinaceous foods, and compared four of them with combustion processes, and the results have been eminently satisfactory. I have also applied it to malt extract in solution, to cocoa, to tea and to coffee.

Two unalyses of water have been made by this moist process; the result was such as from the general character of the water might be expected, but no check combustion was made, so I am ignorant as to how the two methods would compare. 
It seems to be so extremely convenient and its applications so numerous, that any analyst would confer a benefit on us all, if he should make a number of comparative determinations of the total nitrogen in water, milk, broth, \&c., and communicate the results to the Society.

The sulphuric acid I have used, has never been absolutely ammonia free, but it was found easy to make blank experiments and get out a constant factor, but with such a strongly nitrogenous liquid as urine, even this was not necessary, tho orror falling in the third decimal place; on the other hand, in the case of water analysis, an exact correction for the ammoniacal impuritios will of course be important.

Conoluston of the Prockedings of the Socterty of Pubuto Anatrsts. 